\title{
Oats induced villous atrophy in coeliac disease
}

\author{
K E A Lundin, E M Nilsen, H G Scott, E M Løberg, A Gjøen, J Bratlie, V Skar, E Mendez, A Lovik, \\ K Kett
}

The current trend is to allow coeliac disease (CD) patients to introduce oats to their gluten free diet. We sought further data from the clinical setting with regards to oats consumption by coeliac patients. Several oat products were tested for wheat contamination using a commercial enzyme linked immunoassay (ELISA) kit, and six samples were examined by an ELISA using a cocktail of monoclonal antibodies, mass spectrometry, and western blot analysis. Nineteen adult CD patients on a gluten free diet were challenged with $50 \mathrm{~g}$ of oats per day for 12 weeks. Serological testing and gastroduodenoscopy was performed before and after the challenge. Biopsies were scored histologically and levels of mRNA specific for interferon $\gamma$ were determined by reverse transcription-polymerase chain reaction analysis. Oats were well tolerated by most patients but several reported initial abdominal discomfort and bloating. One of the patients developed partial villous atrophy and a rash during the first oats challenge. She subsequently improved on an oats free diet but developed subtotal villous atrophy and dramatic dermatitis during a second challenge. Five of the patients showed positive levels of interferon $\gamma$ mRNA after challenge. Some concerns therefore remain with respect to the safety of oats for coeliacs.

$\mathrm{T}$ he treatment of coeliac disease (CD) has been based on dietary exclusion of proteins from wheat, barley, rye, and oats. Exclusion of oats was based on early feeding experiments but it is certainly possible that oat products used in some of these trials were contaminated by other cereals. There are however several reasons to include oats in the diet of CD patients. Oats may increase the palatability of the diet and would serve as a valuable source of fibre in a diet that is generally fibre deficient.

The possible harmful effect of oats has recently been revisited. In a large study, $92 \mathrm{CD}$ patients were randomised to a standard gluten free diet or a similar diet with oats. Their small intestinal mucosa was unaffected by oats, ${ }^{1}$ and serological normalisation was not delayed. ${ }^{2}$ Eleven patients withdrew during the study. Patients were re-evaluated after five years. ${ }^{3}$ Of 35 patients from the original oats group, 23 were still eating oats. No harmful effect of oats was shown. In a smaller study of $10 \mathrm{CD}$ patients, oats was also well tolerated. ${ }^{45} \mathrm{~A}$ Swedish study where 20 treated CD patients were followed for two years showed that they tolerated large amounts of oats $(100 \mathrm{~g} /$ day $) .^{6}$ Five patients withdrew from the study. ${ }^{6}$ Studies suggesting that oats are safe for patients with dermatitis herpetiformis have also been reported. ${ }^{78}$ Further clinical trials have been requested.

\section{PATIENTS AND METHODS \\ Oats purity testing}

A number of commercial oat products were tested for wheat contamination by an enzyme linked immunoassay (ELISA) kit that detects wheat $\omega$-gliadin (Ridascreen; Food Diagnostics, Oslo, Norway). The method was developed by Skerritt and Hill. ${ }^{9}$ The ELISA kit also identifies rye, and to a much lesser extent, barley and oats. Some oat samples were also tested by western blot, mass spectrometry, and ELISA, as described elsewhere. ${ }^{10-12}$ A total of 120 oat samples from the manufacturer chosen for our clinical challenge were also tested by a similar kit (BioKits; Tepnel, Manchester, UK) at the Veterinary Institute, Oslo, Norway (summary in English: http:/www.snt.no/dokumentasjon/rapporter/snt rapporter/ 200202.html). This kit uses the same monoclonal antibody as the Ridascreen kit but has been produced by another manufacturer.

\section{Clinical challenge}

Nineteen adult CD patients (two males) participated in the study. All had been diagnosed with CD based on duodenal villous atrophy followed by clinical and histological improvement on a standard gluten free diet. All had a control biopsy taken at a clinical follow up during the last 12 months before the clinical challenge. The time of the prechallenge biopsy is presented in table 2. Before starting to consume oats, volunteers submitted to a standard ${ }^{13} \mathrm{C}$-D-xylose breath test. Gastrointestinal symptoms and food intake were measured before, during the challenge, and after the end of the study at 12 weeks. Daily intake of oats was $50 \mathrm{~g}$. On the last day of the challenge period, a new ${ }^{13} \mathrm{C}$-D-xylose breath test and a gastroduodenoscopy using an Olympus GIF-T140 scope was performed, and biopsies obtained with jumbo forceps. Biopsies were scored according to the criteria proposed by Marsh and modified by Oberhuber and colleagues. ${ }^{13} \operatorname{IgA}$ antigliadin antibodies (AGA), antiendomysium antibodies (EMA), and later also antitissue transglutaminase (tTG) were analysed in a routine laboratory (Fürst's Laboratorium, Oslo, Norway). The study was approved by the regional ethics committee. All participants gave informed written consent.

\section{mRNA analysis}

Biopsies were bedside snap frozen in liquid $\mathrm{N}_{2}$, and RNA was isolated and reverse transcribed (RT) as described elsewhere. $^{14}$ A specific polymerase chain reaction (PCR) for interferon gamma (IFN- $\gamma$ ) was performed. Those samples that were positive in the standard RT-PCR were subjected to quantitative PCR. ${ }^{14}$

Abbreviations: $C D$, coeliac disease; ELISA, enzyme linked immunoassay; RNA, ribonucleic acid; RT-PCR, reverse transcriptionpolymerase chain reaction; IFN- $\gamma$, interferon $\gamma$; ppm, parts per million; $M S$, mass spectrometry; AGA, antigliadin antibodies; $T T$, tissue transglutaminase; EMA, antiendomysium antibodies 
Table 1 Six samples analysed for gluten content

\begin{tabular}{lll}
\hline Sample & $\begin{array}{l}\text { Gluten level (ppm) by } \\
\text { WB, MS, ELISA* }\end{array}$ & Ridascreen \\
\hline 1 & $18.0-23.0$ & Negative \\
2 & $13.0-17.0$ & Negative \\
3 & $1.6-<1.5$ & Negative \\
4 & $>>400$ & Positive (0.03\%) \\
5 & $<1.5$ & Negative \\
6 & $<1.5$ & Negative \\
\hline
\end{tabular}

*Level of gluten as determined by a combination of western blot (WB), mass spectrometry (MS), and enzyme linked immunoassay (ELISA) using a cocktail of antibodies. The Ridascreen test has a limit of 5 ppm $(0.001 \%)$. We tested 25 other samples and the Veterinary Institute, Oslo, tested 120 samples from this manufacturer without finding any positive results.

\section{RESULTS}

\section{Oats purity}

We first tested oat samples from the largest Norwegian manufacturer of oats for the general market. They showed variable contamination of wheat or rye ranging from none to unacceptably high levels. The test method (ELISA) is unable to distinguish between wheat and rye. One of 12 products from Finland was also contaminated. The clinical challenge of the present study was therefore performed using oats from a single manufacturer (Norsk Bokhvetedyrkerlag, Arendal, Norway). The oats were harvested from fields where no wheat, rye, barley, or oats had been grown during the last 10 years. Special harvesting equipment and an industrial processing site were used exclusively for the purpose of producing contaminant free oats. We tested 25 samples, and 120 samples were analysed by a reference laboratory. No contamination was detected in any of the samples. Six samples were later analysed by western blot, ELISA test using a cocktail of antibodies, and MALDI-TOF mass spectrometry (MS) (table 1). The "gluten content" in five of these samples was estimated to lie between $<1.5$ parts per million $(\mathrm{ppm})$ and $23 \mathrm{ppm}$. Two of the samples with $<1.5 \mathrm{ppm}$ were from the oats that our oat intolerant patient had been eating (see below). We found contamination ( $>400 \mathrm{ppm}$ by western blot, cocktail ELISA, and MS, 300 ppm by Ridascreen test) in one sample. The source of contamination could not be precisely determined but western blot analysis suggested barley. MS could not determine the source of the contamination due to the large amounts of oat avenins in the sample, and the fact that barley and oats are hardly distinguishable by MS. In another sample from the bottom of the same bag, we later found $<1.5 \mathrm{ppm}$. Thus a single or a few seeds of barley may have been present in the bag.

\section{Clinical challenge}

Nineteen $C D$ patients agreed to start the challenge. One patient (No 8 in table 2) withdrew from the study after two weeks due to gastrointestinal symptoms and a non-specific feeling of unwellness (the patient did not wish to be subjected to further investigation). Another patient (No 16 in table 2) presented more severe gastrointestinal symptoms with diarrhoea and bloating. These symptoms resolved towards the end of the challenge. Biopsies taken after 12 weeks of oats intake did not, in this case, show any mucosal changes. Several of the other coeliacs experienced initial bloating and discomfort. All of the patients took a ${ }^{13} \mathrm{C}$ D-xylose test immediately before starting the challenge. At this time, patient No 10 with a partial villous atrophy compatible with not fully recovered mucosa (Marsh $3 \mathrm{~A}$ lesion) had a pathological ${ }^{13} \mathrm{C}$-D-xylose absorption test result. This patient had a normal test result after the challenge. When repeated at the end of the challenge, only the patient that developed villous atrophy (No 5) had a pathological pattern (data not shown). The histology of the small intestinal mucosa was compared between biopsies taken prior to the study and on the last day of challenge. Most of the patients had a normal (Marsh 0) or near normal (Marsh type 1) small intestinal mucosa before the challenge. Three patients (Nos 4, 10, and 14) had a partial villous atrophy before the challenge (Marsh 3A lesion). These patients had been on a gluten free diet for two, three, and five years, respectively. These three patients were on a strict gluten free diet and had a more pronounced mucosal lesion at the time of diagnosis (data not shown). Small intestinal biopsies taken after the oats challenge showed either unchanged histology or improved histology, with one exception (discussed later). Levels of IgA-AGA were unchanged during the challenge (data not shown). All patients had a negative IgAEMA before and after the challenge (data not shown). Levels of IgA-anti-tTG were below that of the negative control serum (that is, the reference level) before and after the challenge in all patients (data not shown). In the mucosa of treated coeliacs on a standard gluten and oats free diet, the level of mRNA for IFN- $\gamma$ is usually below $1 \times 10^{3}$ transcripts per $\mu \mathrm{g}$ total RNA. ${ }^{14}{ }^{15}$ Interestingly, after the oats provocation

\begin{tabular}{ccccccc} 
Table 2 & \multicolumn{2}{l}{ Marsh score and IFN- $\gamma$ levels before and after the oats challenge } \\
\hline $\begin{array}{l}\text { Patient } \\
\text { No }\end{array}$ & GFD(y) & $\begin{array}{l}\text { Prebiopsy } \\
\text { (months) }\end{array}$ & $\begin{array}{l}\text { Marsh score } \\
\text { (before) }\end{array}$ & IFN- $\gamma$ (before) & $\begin{array}{l}\text { Marsh score } \\
\text { (after) }\end{array}$ & IFN- $\gamma$ (after) \\
\hline 1 & 2 & -12 & 0 & $<1 \times 10^{3}$ & 0 & $<1 \times 10^{3}$ \\
2 & 14 & -12 & 1 & $<1 \times 10^{3}$ & 0 & $<1 \times 10^{3}$ \\
3 & 15 & -10 & 0 & $<1 \times 10^{3}$ & 0 & $<1 \times 10^{3}$ \\
4 & 5 & -5 & $3 a$ & $6.5 \times 10^{4}$ & 1 & $8.2 \times 10^{4}$ \\
5 & 3 & -6 & 1 & $<1 \times 10^{3}$ & $3 a$ & $6.0 \times 10^{4}$ \\
6 & 2 & -12 & 0 & $<1 \times 10^{3}$ & 0 & $<1 \times 10^{3}$ \\
7 & 5 & -12 & 0 & $<1 \times 10^{3}$ & 0 & $<1 \times 10^{3}$ \\
8 & 2 & -5 & 0 & $<1 \times 10^{3}$ & ND & ND \\
9 & 2 & -2 & 1 & $<1 \times 10^{3}$ & 1 & $4.3 \times 10^{4}$ \\
10 & 3 & -12 & $3 a$ & $<1 \times 10^{3}$ & 1 & $<1 \times 10^{3}$ \\
11 & 11 & -10 & 1 & $N D$ & 1 & $<1 \times 10^{3}$ \\
12 & 3 & -10 & 0 & $<1 \times 10^{3}$ & 0 & $<1 \times 10^{3}$ \\
13 & 2 & -11 & 0 & $<1 \times 10^{3}$ & 0 & $6.6 \times 10^{4}$ \\
14 & 2 & -12 & $3 a$ & $<1 \times 10^{3}$ & $3 a$ & $1.3 \times 10^{5}$ \\
15 & 2 & -5 & 1 & $<1 \times 10^{3}$ & 1 & $<1 \times 10^{3}$ \\
16 & 30 & -12 & 0 & $<1 \times 10^{3}$ & 0 & $<1 \times 10^{3}$ \\
17 & 3 & -11 & 0 & $<1 \times 10^{3}$ & 0 & $<1 \times 10^{3}$ \\
18 & 11 & -12 & 0 & $<1 \times 10^{3}$ & 0 & $<1 \times 10^{3}$ \\
19 & 17 & -2 & 0 & $<1 \times 10^{3}$ & 0 & $<1 \times 10^{3}$ \\
\hline
\end{tabular}

IFN- $\gamma$, interferon $\gamma$ specific transcripts per $\mu$ g RNA; GFD, gluten free diet; ND, not detected. 
period, five coeliacs had detectable levels of mRNA for IFN- $\gamma$ (table 2). One of these five also had a positive level before the provocation, and one patient was only tested afterwards. With one exception, these five individuals had a histologically normal or near normal mucosa. The exception is discussed in the following section. Of the 19 participants, three chose not to continue consuming oats after having completed the challenge, and one patient refused further follow up.

\section{Case report}

The patient (No 5 in table 2) was a 45 year old woman in academic employment. She presented a positive endomysium test and a subtotal villous atrophy while on a normal diet in 1997. She recovered, as expected, on a standard gluten free diet, both clinically, serologically, and histologically. She was then diagnosed with $\mathrm{CD}$. Her occupation involves travelling; she has had only very few unintentional dietary relapses. Clinically, she is a well treated but sensitive CD patient. She was healthy before the oats challenge. The last biopsy before the challenge was taken six months in advance, and showed a Marsh type 1 lesion (fig 1). In snap frozen biopsies, we found $<1 \times 10^{3}$ IFN- $\gamma$ specific transcripts per $\mu$ g RNA. During the planned 12 week challenge, she developed slight dermatitis, villous atrophy (Marsh 3A lesion), and positive levels of mRNA for IFN- $\gamma\left(6.0 \times 10^{4}\right.$ IFN- $\gamma$ specific transcripts per $\mu \mathrm{g}$ RNA). The slight dermatitis caused no concern to us or the patient. After the first 12 weeks, she discontinued eating oats. She then agreed to enter a new clinical challenge after 12 weeks on a gluten free and oats free diet. Her mucosa had then returned to nearly normal (Marsh 1), and the rash had disappeared. Quantitative RT-PCR demonstrated $4.8 \times 10^{4}$ IFN- $\gamma$ specific transcripts per $\mu \mathrm{g}$ RNA. She started eating oats. However, after eight weeks she was very ill with diarrhoea and a dramatic itching dermatitis; the challenge clearly had to be discontinued. Biopsies obtained by gastroduodenoscopy showed that she had developed a more severe subtotal villous atrophy (Marsh 3B lesion) and levels of RNA for IFN- $\gamma$ had increased to $1.3 \times 10^{5}$ transcripts per $\mu \mathrm{g}$ RNA. Dermatitis was described by the dermatologist as clinically compatible with dermatitis herpetiformis on the extremities and her back, and there were psoriasoform plaques on her scalp and on one leg. A single skin biopsy failed however to demonstrate IgA deposits (data not shown). The dermatitis was treated in the first two months with topical steroids and retraction of oats, with limited clinical effect. Thereafter, she was treated with UVA/UVB and experienced good clinical effects. She came back for a control gastroduodenoscopy one year after the challenge. We found that the mucosa had improved to a Marsh 3A lesion so she had not yet returned to the prechallenge situation.

\section{Follow up after 1.5 years}

Patients were allowed to eat pure oats at their own will, after the study challenge. After 1.5 years, 15 patients agreed to return for follow up, including gastroduodenoscopy. Of these 15 patients, 12 regularly consumed oats, although usually less than $50 \mathrm{~g} /$ day. Their small intestinal histology was still satisfactory (Marsh type 0 or Marsh type 1). All had normal serology and expressed their satisfaction with the addition of oats to their diet. Two oats eating patients (Nos 1 and 15 in table 2) who were negative for IFN- $\gamma$ mRNA after the 12 week challenge period showed a positive signal at follow up. The level was not quantitated but was not associated with mucosal deterioration.

\section{DISCUSSION}

Here we have shown that oats with, at most, negligible contamination with other cereals is commercially available in Norway. These oats were well tolerated by the majority of 19
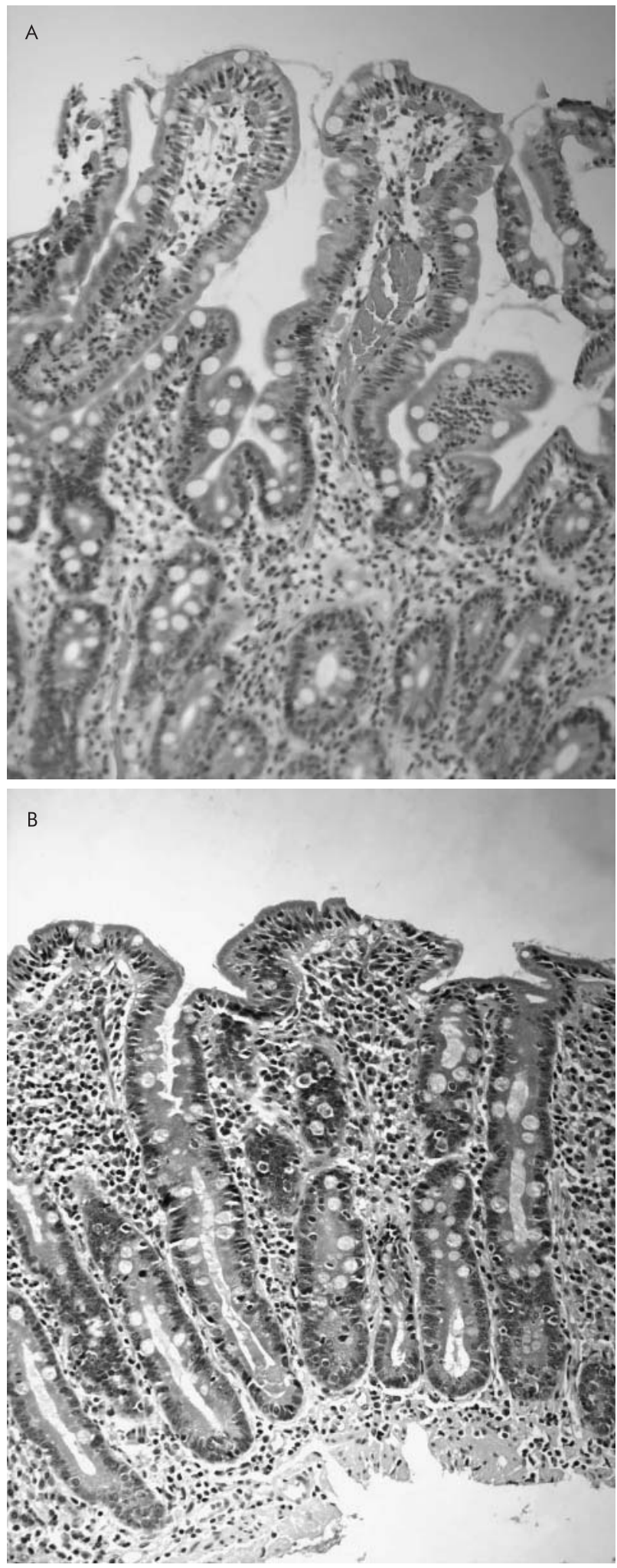

Figure 1 Small intestinal morphology of patient No 5 in table 2 before (A, Marsh 1 lesion) and after (B, Marsh 3B lesion) she had been eating oats. Haematoxylin-eosin staining, original magnification $200 x$.

treated CD patients in a challenge study. However, we found one CD patient who was intolerant to oats.

An important issue regarding the present study pertains to the purity of oats used. We chose to test the oats used in the study for purity using a commercially available ELISA kit. 
The test kit uses an antibody against $\omega$-gliadin. This test detects wheat and rye, but to lesser extent barley. The manufacturer of the oats selected for use in the present study took several precautions to avoid contamination of the oats with other cereals. It was reassuring that testing of a large number of 150 samples failed to yield a positive test. With the unexpected result of the clinical challenge in mind, we tested some of the samples with more technically advanced procedures. We then found that one of the sacks of oats was contaminated at the top of the sack but not at the bottom. Importantly, two samples from the oats consumed by our oats intolerant patient were found to be pure oats. Taken together, we find it likely that the oats used in the present study were sufficiently pure and adhered to the limitations suggested by the revised Codex standard limit of $20 \mathrm{ppm}$ for naturally gluten free food. ${ }^{16}$

Some aspects of the clinical challenge should be discussed. We chose to challenge patients for 12 weeks as this period is comparable with other studies and was expected to be sufficient for detecting a deleterious response. For the single evidently intolerant patient, the challenge time was clearly sufficient. She developed mucosal changes and dermatitis during the challenge. Dermatitis clinically resembled dermatitis herpetiformis but a single biopsy did not demonstrate IgA deposits typical of this disease. However, even though a typical IgA deposit is diagnostic of dermatitis herpetiformis, ${ }^{17}$ it is sometimes necessary to obtain repeated biopsies and even true negative cases may exist. ${ }^{18}$ However, the dermatitis was in time directly related to oats consumption and waned over 3-4 months following retraction of oats. A weakness of the present study is that some time elapsed between the prechallenge biopsy and the actual challenge. This may not be optimal but we considered it unlikely that these adult well treated patients should develop mucosal changes during the run in period.

Our findings are at odds with previously reported clinical studies. ${ }^{1-6}$ We noted that introduction of oats led to changes in bowel habits and some abdominal discomfort for several of the patients. This experience may have been noted previously but is important all the same. It may be used to reassure coeliacs starting with oats that this experience appears to be normal and will likely pass. The major difference is that one of the patients was intolerant to oats. This has not been reported previously. Moreover, if the total number of patients from clinical challenge studies is considered, oats intolerance appears to be a rare event.

After the present challenge study, we have met additional patients who were clinically intolerant to oats (dermatitis, abdominal pain, and general anaphylactoid-like reactions). None was willing to ingest oats again. Thus we consider intolerance of oats in CD as a probable entity.

Although not fully understood at this stage, it is however interesting to note that some of the patients had positive levels of mRNA for IFN- $\gamma$ but no corresponding histological abnormalities. We consider IFN- $\gamma$ as a sign of T cell activation but it may not be directly responsible for the villous atrophy seen in $\mathrm{CD} .{ }^{19}$ The relevance of this finding is limited by the fact that a control group of CD patients who were abstinent from oats were not included in our challenge study. However, we have previously reported findings that show that well treated coeliacs usually do not express IFN- $\gamma$ mRNA in their small intestinal mucosa. ${ }^{14}{ }^{15}$

The present data support the notion that most CD patients tolerate oats in their diet. Contamination of commercial oats by other cereals is a problem and coeliacs should select oats from manufacturers that are devoted to producing oats without such contaminants. However, the finding that even pure oats can induce villous atrophy and dermatitis in one CD patient raises some concern.

\section{ACKNOWLEDGEMENTS}

We thank the nursing personnel at the endoscopy units at Rikshospitalet and Ullevaal sykehus, and the technical staff at LIIPAT and Institute of Immunology, at Rikshospitalet, for invaluable assistance. The study received support from Regal, Freia Chokolade Fabriks Medicinske Fond, Medinnova, Astra, the Norwegian Coeliac Disease Association, and EXTRA funds from the Norwegian Foundation for Health and Rehabilitation. We thank Dr Andrew S Louka for critically reading the manuscript.

\section{Authors' affiliations}

K E A Lundin, A Løvik, K Kett, Department of Medicine, Rikshospitalet, Oslo, Norway

E M Nilsen, LIIPAT, Institute of Pathology, Rikshospitalet and University of Oslo, Oslo, Norway

H G Scott, Department of Pathology, Rikshospitalet, Oslo, Norway E M Løberg, Department of Pathology, Ullevaal University Hospital, Oslo, Norway

A Gjøen, Department of Medicine, Ullevaal University Hospital, Oslo, Norway

J Bratlie, Institute for Medical Research, Rikshospitalet and University of Oslo, Oslo, Norway

V Skar, Department of Medicine, Lovisenberg Hospital, Oslo, Norway E Mendez, Unidad de Analisis Estructural Proteinas, Centro Nacional de Biotechnologica, CSIC, Madrid, Spain

Correspondence to: Dr K E A Lundin, Department of Medicine Rikshospitalet, N-0027 Oslo, Norway; knut.lundin@rikshospitalet.no

Accepted for publication 27 May 2003

\section{REFERENCES}

1 Janutainen EK, Pikkarainen PH, Kemppainen TA, et al. A comparison of diets with and without oats in adults with celiac disease. N Engl J Med 1995;333:1033-7.

2 Janutainen EK, Kemppainen TA, Pikkarainen PH, et al. Lack of cellular and humoral immunological responses to oats in adults with coeliac disease. Gut 2000;46:327-31.

3 Janatuinen EK, Kemppainen TA, Julkunen RJK, et al. No harm from five year ingestion of oats in coeliac disease. Gut 2002;50:332-5.

4 Srinivasan $\mathrm{U}$, Leonard $\mathrm{N}$, Jones $\mathrm{E}$, et al. Absence of oats toxicity in adults with coeliac disease. B Med J 1996;313:1300-1.

5 Srinivasan U, Jones E, Weir DG, et al. Lactase enzyme, detected immunohistochemically, is lost in active celiac disease, but unaffected by oats challenge. Am J Gastroenterol 1999;94:2936-41.

6 Størsrud S, Olsson M, Lenner RA, et al. Adult coeliac patients do tolerate large amounts of oats. Eur J Clin Nutr 2003;57:163-9.

7 Hardman CM, Garioch JJ, Leonard JN, et al. Absence of toxicity of oats in patients with dermatitis herpetiformis. N Engl J Med 1997;337: 1884-7.

8 Reunala T, Collin P, Holm K, et al. Tolerance to oats in dermatitis herpetiformis. Gut 1998:43:490-3.

9 Skerritt JH, Hill AS. Enzyme immunoassay for determination of gluten in foods: collaborative study. J Assoc Anal Chem 1991;74:257-64.

10 Camafeita E, Alfonso P, Mothes T, et al. Matrix-assisted laser desorption/ ionization time-of-flight mass spectrometric micro-analysis: the first nonimmunological alternative attempt to quantify gluten gliadins in food samples. J Mass Spectrom 1997;32:940-7.

11 Camafeita E, Mendez E. Screening of gluten avenins in foods by matrixassisted laser desorption/ionization time-of-flight mass spectrometry. J Mass Spectrom 1998;33:1023-8.

12 Sorell L, Lopez JA, Valdes I, et al. An innovative sandwich ELISA system based on an antibody cocktail for gluten analysis. FEBS Lett 1998;439:46-50.

13 Oberhuber G, Granditsch G, Vogelsang H. The histopathology of coeliac disease: time for a standarized report scheme for pathologists. Eur J Gastroenterol Hepatol 1999;1 1:1185-94.

14 Nilsen EM, Scott H, Lundin KEA, et al. Gluten induces an intestinal cytokine response strongly dominated by interferon- $\gamma$ in patients with celiac disease. Gastroenterology 1998;115:551-63.

15 Lundin KEA, Kett K, Scott H, et al. Relation between degree of villous atrophy and IFN-gamma mRNA in the small intestine of celiac patients. J Pediatr Gastroenterol Nutr 2000;31:S15.

16 Stern M, Ciclitira PJ, van Eckert R, et al. Analysis and clinical effects of gluten in coeliac disease. Eur J Gastroenterol Hepatol 2001;13:741-7.

17 Reunala TL. Dermatitis herpetiformis. Clin Dermatol 2001;19:728-36.

18 Beutner EH, Baughman RD, Austin BM, et al. A case of dermatitis herpetiformis with $\lg A$ endomysial antibodies but negative direct immunofluorescent findings. J Am Acad Dermatol 2000;43:329-32.

19 MacDonald TT, Bajaj-Elliott M, Pender SL. T cells orchestrate mucosal shape and integrity. Immunol Today 1999;20:505-10. 